\title{
Preparation and Monitoring of Small Animals in Renal MRI
}

\section{Tamas Kaucsar, Adam Hosszu, Erdmann Seeliger, Henning M. Reimann, and Andrea Fekete}

\begin{abstract}
Renal diseases remain devastating illnesses with unacceptably high rates of mortality and morbidity worldwide. Animal models are essential tools to better understand the pathomechanism of kidney-related illnesses and to develop new, successful therapeutic strategies. Magnetic resonance imaging (MRI) has been actively explored in the last decades for assessing renal function, perfusion, tissue oxygenation as well as the degree of fibrosis and inflammation. This chapter aims to provide an overview of the preparation and monitoring of small animals before, during, and after surgical interventions or MR imaging. Standardization of experimental settings such as body temperature or hydration of animals and minimizing pain and distress are essential for diminishing nonexperimental variables as well as for conducting ethical research.

This publication is based upon work from the COST Action PARENCHIMA, a community-driven network funded by the European Cooperation in Science and Technology (COST) program of the European Union, which aims to improve the reproducibility and standardization of renal MRI biomarkers.
\end{abstract}

Key words Magnetic resonance imaging (MRI), Kidney, Rodent surgery, Anesthesia

\section{Introduction}

Renal diseases are devastating illnesses with unacceptably high rates of mortality and morbidity worldwide. End-stage renal disease is the final stage of chronic kidney disease (CKD) characterized by complete loss of kidney function. Global prevalence is estimated to be $8-16 \%$ and the overall years of life lost due to premature death is third behind AIDS and diabetes mellitus [1]. Kidney diseases create a huge burden on healthcare systems; thus, the social and economic impact of prevention and early treatment would be enormous. Several publications have highlighted the need for new, effective therapies as well as superior diagnostic tools.

At present, diagnosis of kidney disease is difficult and often involves invasive procedures. Conventional markers of renal function such as serum creatinine and blood urea nitrogen are poorly sensitive and poorly selective, as they represent a delayed indication 
of functional change that lags behind structural deterioration during the early stage of acute kidney injury (AKI). Currently kidney biopsy is the single method to assess renal microstructure in humans, but it is an invasive procedure and sampling bias can alter results. Thus, noninvasive, in vivo imaging methods are crucial for the adequate assessment of kidney function, oxygenation, and structure in both preclinical and clinical setups. Importantly, stateof-the-art functional MRI techniques are available to determine tissue oxygenation, perfusion, fibrosis, inflammation, or tissue edema that can be used as biomarkers of renal disease [2]. MRI affords full kidney coverage, soft tissue contrast that helps to differentiate the renal layers, second-to-minute temporal resolution, support of longitudinal studies and high anatomical detail without the use of ionizing radiation $[3,4]$.

However, imaging rodents can be challenging because in contrast to human studies, imaging of animals requires anesthesia to physically restrain the animals and minimize their gross motion. Anesthetic agents can profoundly alter physiology of the experimental animal and may thus influence the image data acquired. It is therefore necessary to use the most appropriate anesthetic compound and to monitor the physiology of anesthetized animals during image acquisition [5-7].

It is essential that researchers use animals in scientifically, technically, and humanely appropriate ways. Effective and appropriate animal care before, during, and after experimentation not only is important for the enhancement of animal well-being but can also have a major effect on the quality of research. Hydration status, the type of anesthesia used, or body temperature of the animals during surgery or MRI measurements, as well as postoperative care are all factors that can affect results, and thus should be carefully planned prior to the intervention. Standard protocols can be modified, but should not compromise the well-being of the animals.

This chapter summarizes preoperative procedures, advantages and disadvantages of different anesthetic agents, monitoring of physiological functions during surgical or imaging procedures, and how these challenges can be successfully addressed.

This chapter is part of the book Pohlmann A, Niendorf T (eds) (2020) Preclinical MRI of the Kidney-Methods and Protocols. Springer, New York.

\section{Hydration}

Animals can experience considerable fluid loss during surgery mainly due to evaporation from open body cavities or blood loss. Rodents are particularly vulnerable to intraoperative fluid loss because of their small size and relatively small total body fluid content. Warm, sterile isotonic fluids should be administered at $3-5 \%$ of the body weight subcutaneously or intraperitoneally 
prior to and at the end of surgery. Alternatively, isotonic fluid can be continuously administered via intravenous infusion or even via intra-arterial infusion in case a catheter has already been placed into an artery for monitoring of blood pressure and heart rate. The operative field should be irrigated with warm saline and drying out of tissues should be avoided $[8,9]$. In any case, quantity of hydration has to be logged and/or standardized to eliminate nonexperimental variable factors. For example, with proper hydration tubular reabsorption, an energy-dependent process can be spared. Hence, some procedures such as ischemia will have less effect on renal injury in well hydrated animals. Intraoperative fluid replacement is also important because during the recovery phase water intake is usually reduced, even though ad libitum water access is usually ensured after surgery.

An ophthalmic lubricating ointment should be applied to the eyes to protect the cornea from drying out.

\section{Anesthesia}

The use of anesthetics for surgical or in vivo imaging procedures comes with an inevitable autonomic nervous system depression, causing cardiovascular and respiratory depression, hypothermia, and altered metabolism [10]. Different anesthetics influence these physiological processes differently; thus, various anesthetic agents should be selected for different experimental models. For example, anesthesia used during renal ischemia-reperfusion injury (IRI) surgery has an important impact on the extent of injury. Numerous studies showed that anesthetics are renoprotective due to their antiinflammatory, antiapoptotic, or antinecrotic effect, independently of the way of administration. Also different anesthetics impose different effects on vasomotion (dilation and constriction). Vasomotion, in turn, has a direct impact on local renal blood volume fraction, which affects the measure $\mathrm{T}_{2}{ }^{*}$. Furthermore, it influences perfusion, which affects the blood oxygenation and ultimately $\mathrm{T}_{2}$ * as well. $\mathrm{R}_{2}{ }^{*}$ - the transverse relaxation rate — can vary by more than $100 \%$ depending on the anesthetic regimen [11]. In animal experiments inhalable and injectable anesthetics are both popular. Advantage of inhalable anesthetics (e.g., halothane or fluranes) are that they are rapidly eliminated through the lungs; therefore, incidence of fatal events is lower and fast recovery can be achieved. On the other hand, they are frequently irritant, and it is hard to set a precise dosage; hence, it is easier to cause hypoxia, and if apnea occurs loss of consciousness will last longer. Injectable anesthetics (barbiturates, ketamine, propofol, etc.) promote a quick loss of consciousness with better control of cardiopulmonary function and induce anesthesia at a lower dose. They frequently influence blood pressure, and hypothermia can also develop. Although barbiturates can be precisely dosed through intravenous administration, the 


\subsection{Injectable Anesthetics}

intraperitoneal, subcutaneous, or intramuscular injection of other injectable anesthetics may lead to variable levels of anesthesia. Because of the short time of action (with the exception of urethane) repeated dosing or constant infusion of injectable anesthetics is sometimes needed, prolonging recovery time [12]. During procedures respiratory rate and alertness of the animal should be followed. Anesthesia should be intensified at the first signs of alertness such as movement of whiskers or reflex triggered by pinching the toes outside the MR environment. It should be noted that deeper anesthesia is needed for surgical interventions than for MRI alone.

Ketamine is one of the safest and most widely used injectable anesthetics in animal surgeries because it does not require intravenous access and cardiorespiratory depression occurs only at a much higher dose than what is needed for anesthesia [13]. Ketamine is frequently used in combination with other anesthetics like $\alpha 2$ agonists (xylazine) or benzodiazepines to prevent muscle rigidity and produce more stable anesthesia [7]. In these cases, the dose of ketamine can be reduced. However, ketamine may reduce IRI in rats in low doses, when its antioxidant capacity is the greatest [14]. On the other hand, ketamine may be harmful at higher doses due to its sympathomimetic effect [15]. Despite the low cardiovascular and respiratory influence of ketamine alone [16], cardiac influences, like hypotension with minimal respiratory depression must also be considered when using ketamine together with xylazine [17]. Substantial cardiovascular effects (bradycardia, hypotension) were observed when acepromazine, buprenorphine, or carprofen was also added to the ketamine-xylazine combination. Nevertheless, the addition of acepromazine led to stable hemodynamic parameters while sustaining adequate anesthesia for performing surgical procedures [18]. Cerebral hemodynamics are also affected by ketamine-xylazine combinations, which may cause reduction of cerebral blood flow thus affecting brain oxygenation and leading to interferences with several imaging procedures [19]. Metabolic changes could also occur during ketamine-xylazine anesthesia. Decreased insulin secretion by pancreatic $\beta$ cells together with the blockade of ATP-dependent potassium channels may cause elevated levels of blood glucose and potassium [20].

Short and ultrashort acting barbiturates (pentobarbital and thiopental, respectively) are also frequently used in animal experiments. They are relatively inexpensive and have a rapid and smooth onset of action as well as recovery [21]. On the other hand, they have small therapeutic margin and even though they can be precisely dosed via intravenous administration, the risk of fatal events is much higher than for ketamine [22]. However, their use is limited in renal ischemia-reperfusion surgery, since they reduce blood pressure and thus blood flow to the kidney. Although by lowering pentobarbital dose there are less cardiovascular side effects, poor anesthetic depth, and serious respiratory depression with low 
oxygen saturation can be expected during pentobarbital monoanesthesia [17]. Thiopental decreased malondialdehyde levels and reduced histopathologic damage to the kidneys after IRI in subanesthetic doses [15]. Moreover, clinically high doses of thiopental effectively protected against renal IRI [23]. What may lie behind this renoprotective effect is that thiopental is also an antioxidant [24] and inhibits neutrophil function [25]. Thiopental might also depress brain metabolism and thus elevate brain glucose content in the cortex [26]; however, pentobarbital has no effect on blood glucose levels [20].

Propofol is a rapid acting anesthetic, with short recovery duration, thus convenient for short procedures [10]. Propofol has a serious respiratory depressant effect and decrease in cerebral blood flow and intracranial pressure have also been reported [27]. The renoprotective effect of propofol via reduced production of proinflammatory cytokines, less neutrophil infiltration, and hence lower reactive oxygen species accumulation is well documented $[15,28$, 29]. Due to its renoprotective effect, propofol is currently not used in experimental models of renal injury.

Urethane is extensively used alone or in combination with ketamine and xylazine in nonrecovery procedures. Advantages are its long-lasting (several hours) surgical plane of anesthesia [30, 31] and least effects on cardiovascular and respiratory control compared to other anesthetics $[32,33]$. At least $8 \mathrm{~h}$ of fasting of the animals is recommended before urethane anesthesia.

3.2 Inhalable Anesthetics
Halogenated ethers are the preferred volatile anesthetics during animal experiments. Due to their rapid onset and short recovery time and low metabolism the side effects of inhalation anesthesia can be well controlled [10]. For example, isoflurane is preferred in cardiovascular studies, since it causes less hemodynamic depression than injectable anesthetics $[17,34]$. It also reduces peripheral resistance thus hypotension might occur [35]. On the other hand, the rate of respiratory depression is higher than by injectable anesthetics; therefore, respiratory rate monitoring is indispensable when adjusting gas concentration. By maintaining high tidal volumes a stable oxygen saturation may be achieved during isoflurane anesthesia [17]. Yet isoflurane-induced respiratory depression results in hypercapnia, leading to substantial vasodilation in the brain and increased baseline cerebral blood flow [36]. To maintain physiological cerebral blood flow mechanical ventilation of the animal is recommended. In contrast, hypercapnia has only negligible effects on vasomotion in the kidney [37]. However, vasodilatory effects of isoflurane may be reflected in renal $\mathrm{T}_{2}{ }^{*}$ that has been found substantially higher compared to other anesthetics [11]. Metabolic changes have also been reported: isoflurane decreases insulin production, thus leads to higher blood glucose levels [20]. 
There is increasing evidence that halogenated ethers provide significant protection against renal IRI, which effect is differential: desflurane being less protective than isoflurane or sevoflurane [38]. Moreover, anesthesia with isoflurane has a preconditioning effect on renal IRI, with the involvement of JNK and ERK protein kinases [39]. When compared to propofol, isoflurane provided the same level of protection against ischemia reperfusion injury and therefore should be used with caution [40].

\section{Physiological Monitoring}

\subsection{Body Temperature}

Due to their large surface to body weight ratio rodents lose heat rapidly especially if the abdominal cavity is exposed. Hypothermia might further be exacerbated by the use of cold, dry gases, hair clipping, or the administration of cold fluids. Hairless strains and neonates which are considered exothermic in the early stages of life are especially susceptible to hypothermia because of their diminished insulation. Hypothermia poses multiple risks during anesthesia and recovery, including infection, bleeding complications and cardiac dysfunction. These factors may be the difference between life and death and if the animal survives, the difference between good and unreliable data; therefore, it is highly recommended that an external heat source be used during surgery. Adjustable heating pads or circulating warm water blankets usually allow a good maintenance of body temperature. Homogeneous warming of large surface areas of the animal's body-instead of using planar heating pads that provide comparably smaller contact areas-permits to reduce the heating temperature and allows for better maintenance of overall physiological body temperature [41]. For accurate control, a thermometer should be used to measure the temperature rectally and-if abdominal surgery is part of the procedure-also a second temperature probe placed close to the kidney should be used. Here it is important to consider the possible interactions of the temperature probe with the MRI. Conventional resistive probes with metallic cables may suffer from electrical currents induced by the time-varying magnetic field gradients used during imaging. This might disturb the temperature measurement and even heat up the cables. Use of fiber optical probes helps to avoid these issues but some optical probes experience a sizable offset in the measured temperature with a very strong magnetic field. For instance, a negative offset of $4.7^{\circ} \mathrm{C}$ at a magnetic field strength of $9.4 \mathrm{~T}$ was observed with GaAs-based probes. Some heating pads can automatically regulate the temperature with the help of a thermostat [42]. Too high temperatures can cause protein denaturation and tissue injury, which might result in death.

Kidney temperature during ischemia significantly influences IRI. Body temperature drops after anesthesia, which mitigates IRI 
[9]. Therefore, close control and maintenance of body temperature is needed in order to perform reproducible AKI. Ischemia should only be initiated if the desired stable temperature is set and maintained.

\subsection{Respiration}

4.3 Cardiovascular System
Respiratory monitoring can be achieved by observation of chest motion, depth and character of respiration during surgical interventions. Direct visualization of the animal is not feasible during imaging; therefore, respiratory motion detection systems that are compatible with and safe to use for most imaging modalities should be employed. These systems typically detect breathing motion by compressions of a respiratory sensor placed in contact with the chest.

During MRI, breathing often causes motion artefacts, which can severely compromise imaging acquisitions and hence measures to reduce or eliminate such artefacts should be taken. Gating techniques allow for the synchronization of data acquisition with the respiratory cycle. The largest movement of the abdomen occurs between inspiration and expiration; therefore, this period should be excluded from data acquisition.

Heart rate can be monitored using an electrocardiograph system. Heart rate usually correlates with anesthetic depth. A pulse oximeter can be used to measure arterial $\mathrm{O}_{2}$ saturation, pulse strength, breath rate and blood flow in real time, and can thus detect hypoventilation, airway obstruction, or other problems during anesthesia. Pulse oximeters are not remarkably accurate in rodents, but can detect trends and are nevertheless valuable tools. Whenever possible, cardiovascular monitoring should include continuous blood pressure measurement. For nonrecovery experiments, direct blood pressure (and heart rate) monitoring via a catheter in the femoral or carotid artery connected to a pressure transducer is preferred. Alternatively, an inflatable tail pressure cuff can be used noninvasively [10].

\section{Recovery}

5.1 Analgesia
Proper postoperative care is needed to minimize the loss of animals, to reduce intraexperimental variation and to offer humane conditions for recovery [8]. Body temperature should be maintained within physiological limits until the end of anesthesia, when the animal starts to be active.

If activity is resumed, analgesics may be given without the risk of further respiratory depression. Opioids are most commonly used for this purpose [9]; however, some of them can protect against IRI. For example, morphine and naloxone inhibited superoxide 
anion production after renal IRI in rabbits [43] and naloxone alone can also improve warm renal IRI in dogs [44]. However, buprenorphine, a mixed partial $\mu$-opioid receptor agonist and $\kappa$-and $\delta$-opioid receptor antagonist improved animal health by reducing postsurgical stress response, without interfering with renal IRI [45].

Other analgesics, like $\alpha 2$-agonists are proven to have benefic effect on renal IRI $[46,47]$. Nonsteroidal anti-inflammatory drugs also interfere with the renal IRI model $[48,49]$.

\subsection{Antibiotics}

Although there is a risk for postoperative infections after surgery, there is no indication for empiric use of antibiotic prevention [50]. Focus has to be placed on aseptic surgical infrastructure, cautious animal handling, and well-managed animal facilities (SPF, etc.). If systemic antibiotic use is inevitable, then fluoroquinolones and the trimethoprim-sulfonamide combination are generally recommended, since they are not harmful to the symbiotic intestinal bacterial population of mice [51]. Gentamicin is reported to ameliorate IRI mostly during the reperfusion phase and should not be used in such experiments [52]. Antibiotic administration should be delayed until complete anesthetic recovery takes place because of hypotension and prolonged anesthesia due to their calcium blocking action [51].

\section{Acknowledgments}

This chapter is based upon work from COST Action PARENCHIMA, supported by European Cooperation in Science and Technology (COST). COST (www.cost.eu) is a funding agency for research and innovation networks. COST Actions help connect research initiatives across Europe and enable scientists to enrich their ideas by sharing them with their peers. This boosts their research, career, and innovation.

PARENCHIMA (renalmri.org) is a community-driven Action in the COST program of the European Union, which unites more than 200 experts in renal MRI from 30 countries with the aim to improve the reproducibility and standardization of renal MRI biomarkers.

\section{References}

1. US Renal Data System Annual Report 2016. (2016). https://www.usrds.org/adr.aspx

2. Selby NM, Blankestijn PJ, Boor P, Combe C, Eckardt KU, Eikefjord E, Garcia-Fernandez N, Golay X, Gordon I, Grenier N, Hockings PD, Jensen JD, Joles JA, Kalra PA, Kramer BK, Mark PB, Mendichovszky IA, Nikolic O,
Odudu A, Ong ACM, Ortiz A, Pruijm M, Remuzzi G, Rorvik J, de Seigneux S, Simms RJ, Slatinska J, Summers P, Taal MW, Thoeny HC, Vallee JP, Wolf M, Caroli A, Sourbron S (2018) Magnetic resonance imaging biomarkers for chronic kidney disease: a position paper from the European Cooperation in 
Science and Technology Action PARENCHIMA. Nephrol Dial Transplant 33(suppl_2): ii4-iil4. https://doi.org/10.1093/ndt/ gfy 152

3. Prasad PV (2006) Functional MRI of the kidney: tools for translational studies of pathophysiology of renal disease. Am J Physiol Renal Physiol 290(5):F958-F974. https:// doi.org/10.1152/ajprenal.00114.2005

4. Haque M, Franklin T, Prasad P (2011) Renal oxygenation changes during water loading as evaluated by BOLD MRI: effect of NOS inhibition. J Magn Reson Imaging 33 (4):898-901. https://doi.org/10.1002/jmri. 22509

5. Tremoleda JL, Macholl S, Sosabowski JK (2018) Anesthesia and monitoring of animals during MRI studies. Methods Mol Biol 1718:423-439. https://doi.org/10.1007/ 978-1-4939-7531-0_25

6. Herrmann K, Flecknell P (2019) Retrospective review of anesthetic and analgesic regimens used in animal research proposals. ALTEX 36 (1):65-80. https://doi.org/10.14573/altex. 1804011

7. Reimann HM, Niendorf T (2020) The (un)conscious mouse as a model for human brain functions: key principles of anesthesia and their impact on translational neuroimaging. Front Syst Neurosci 14:8. https://doi.org/10. 3389/fnsys.2020.00008

8. Wei Q, Dong Z (2012) Mouse model of ischemic acute kidney injury: technical notes and tricks. Am J Physiol Renal Physiol 303(11): F1487-F1494. https://doi.org/10.1152/ ajprenal.00352.2012

9. Le Clef N, Verhulst A, D'Haese PC, Vervaet BA (2016) Unilateral renal ischemiareperfusion as a robust model for acute to chronic kidney injury in mice. PLoS One 11 (3):e0152153. https://doi.org/10.1371/jour nal.pone. 0152153

10. Tremoleda JL, Kerton A, Gsell W (2012) Anaesthesia and physiological monitoring during in vivo imaging of laboratory rodents: considerations on experimental outcomes and animal welfare. EJNMMI Res 2(1):44. https://doi.org/10.1186/2191-219x-2-44

11. Niles DJ, Gordon JW, Fain SB (2015) Effect of anesthesia on renal R2 * measured by blood oxygen level-dependent MRI. NMR Biomed 28(7):811-817. https://doi.org/10.1002/ nbm.3314

12. Furtado KS, Andrade FO (2013) Comparison of the beneficial and adverse effects of inhaled and injectable anaesthetics: a mini-review. OA Anaesthetics 1(2):20. https://doi.org/10. 13172/2052-7853-1-2-1006
13. Hedenqvist P, Hellebrekers L (2003) Laboratory animal analgesia, anesthesia, and euthanasia

14. Demirkiran H, Senoglu N, Oksuz H, Dogan Z, Yüzbaşıŏ $\mathrm{F}$, Bulbuloglu $\mathrm{E}$, Inanc Tolun $\mathrm{F}$, Aral M, Ciralik H, Goksu M, Yardimci C (2019) The effects of different doses ketamine on the renal ischemia/reperfusion injury in rats. Eastern J Med 24(2):194-199. https:// doi.org/10.5505/ejm.2019.48658

15. Yuzer H, Yuzbasioglu MF, Ciralik H, Kurutas EB, Ozkan OV, Bulbuloglu E, Atlı Y, Erdogan O, Kale IT (2009) Effects of intravenous anesthetics on renal ischemia/reperfusion injury. Ren Fail 31(4):290-296. https://doi. org/10.1080/08860220902779962

16. Hau J, Schapiro SJ (2010) Handbook of laboratory animal science, volume I: essential principles and practices. CRC Press, Boca Raton

17. Tsukamoto A, Serizawa K, Sato R, Yamazaki J, Inomata $\mathrm{T}$ (2015) Vital signs monitoring during injectable and inhalant anesthesia in mice. Exp Anim 64(1):57-64. https://doi.org/10. 1538/expanim.14-0050

18. Buitrago S, Martin TE, Tetens-Woodring J, Belicha-Villanueva A, Wilding GE (2008) Safety and efficacy of various combinations of injectable anesthetics in BALB/c mice. J Am Assoc Lab Anim Sci 47(1):11-17

19. Lei H, Grinberg O, Nwaigwe CI, Hou HG, Williams H, Swartz HM, Dunn JF (2001) The effects of ketamine-xylazine anesthesia on cerebral blood flow and oxygenation observed using nuclear magnetic resonance perfusion imaging and electron paramagnetic resonance oximetry. Brain Res 913(2):174-179. https:// doi.org/10.1016/s0006-8993(01)02786-x

20. Ochiai $Y$, Iwano $H$, Sakamoto $T$, Hirabayashi M, Kaneko E, Watanabe T, Yamashita K, Yokota H (2016) Blood biochemical changes in mice after administration of a mixture of three anesthetic agents. J Vet Med Sci 78(6):951-956. https://doi.org/10. 1292/jvms.15-0474

21. Ilkiw JE (1992) Advantages and guidelines for using ultrashort barbiturates for induction of anesthesia. Vet Clin North Am Small Anim Pract 22(2):261-264

22. Lopez-Munoz F, Ucha-Udabe R, Alamo C (2005) The history of barbiturates a century after their clinical introduction. Neuropsychiatr Dis Treat l(4):329-343

23. Dogan Z, Yuzbasioglu MF, Kurutas EB, Yildiz H, Coskuner I, Senoglu N, Oksuz H, Bulbuloglu E (2010) Thiopental improves renal ischemia-reperfusion injury. Ren Fail 32 (3):391-395. https://doi.org/10.3109/ 08860221003611752 
24. Almaas R, Saugstad OD, Pleasure D, Rootwelt $\mathrm{T}$ (2000) Effect of barbiturates on hydroxyl radicals, lipid peroxidation, and hypoxic cell death in human NT2-N neurons. Anesthesiology 92(3):764-774. https://doi.org/10. 1097/00000542-200003000-00020

25. Nishina K, Akamatsu H, Mikawa K, Shiga M, Maekawa N, Obara H, Niwa Y (1998) The inhibitory effects of thiopental, midazolam, and ketamine on human neutrophil functions. Anesth Analg 86(1):159-165. https://doi. org/10.1097/00000539-199801000-00032

26. Lei H, Duarte JM, Mlynarik V, Python A, Gruetter R (2010) Deep thiopental anesthesia alters steady-state glucose homeostasis but not the neurochemical profile of rat cortex. J Neurosci Res 88(2):413-419. https://doi.org/10. $1002 /$ jnr.22212

27. Bruns A, Kunnecke B, Risterucci C, Moreau JL, von Kienlin M (2009) Validation of cerebral blood perfusion imaging as a modality for quantitative pharmacological MRI in rats. Magn Reson Med 61(6):1451-1458. https:// doi.org/10.1002/mrm.21779

28. Yuzbasioglu MF, Aykas A, Kurutas EB, Sahinkanat T (2010) Protective effects of propofol against ischemia/reperfusion injury in rat kidneys. Ren Fail 32(5):578-583. https:// doi.org/10.3109/08860220903548940

29. Sanchez-Conde P, Rodriguez-Lopez JM, Nicolas JL, Lozano FS, Garcia-Criado FJ, Cascajo C, Gonzalez-Sarmiento R, Muriel C (2008) The comparative abilities of propofol and sevoflurane to modulate inflammation and oxidative stress in the kidney after aortic cross-clamping. Anesth Analg 106 (2):371-378, table of contents. https://doi. org/10.1213/ane.0b013e318160580b

30. Liu X, Li R, Yang Z, Hudetz AG, Li SJ (2012) Differential effect of isoflurane, medetomidine, and urethane on BOLD responses to acute levo-tetrahydropalmatine in the rat. Magn Reson Med 68(2):552-559. https://doi.org/ $10.1002 / \mathrm{mrm} .23243$

31. Aizawa N, Ogawa S, Sugiyama R, Homma Y, Igawa Y (2015) Influence of urethaneanesthesia on the effect of resiniferatoxin treatment on bladder function in rats with spinal cord injury. Neurourol Urodyn 34 (3):274-279. https://doi.org/10.1002/nau. 22549

32. Maggi CA, Meli A (1986) Suitability of urethane anesthesia for physiopharmacological investigations in various systems. Part 1 : general considerations. Experientia 42 (2):109-114. https://doi.org/10.1007/ bf01952426
33. Ganjoo P, Farber NE, Schwabe D, Kampine JP, Schmeling WT (1996) Desflurane attenuates the somatosympathetic reflex in rats. Anesth Analg 83(1):55-61. https://doi.org/10. 1097/00000539-199607000-00010

34. Kober F, Iltis I, Cozzone PJ, Bernard M (2004) Cine-MRI assessment of cardiac function in mice anesthetized with ketamine/xylazine and isoflurane. MAGMA 17 (3-6):157-161. https://doi.org/10.1007/ s10334-004-0086-0

35. Kersten JR, Lowe D, Hettrick DA, Pagel PS, Gross GJ, Warltier DC (1996) Glyburide, a KATP channel antagonist, attenuates the cardioprotective effects of isoflurane in stunned myocardium. Anesth Analg 83(1):27-33. https://doi.org/10.1097/00000539199607000-00006

36. van Alst TM, Wachsmuth L, Datunashvili M, Albers F, Just N, Budde T, Faber C (2019) Anesthesia differentially modulates neuronal and vascular contributions to the BOLD signal. NeuroImage 195:89-103. https://doi.org/ 10.1016/j.neuroimage.2019.03.057

37. Grosenick D, Cantow K, Arakelyan K, Wabnitz H, Flemming B, Skalweit A, Ladwig M, Macdonald R, Niendorf T, Seeliger E (2015) Detailing renal hemodynamics and oxygenation in rats by a combined nearinfrared spectroscopy and invasive probe approach. Biomed Opt Express 6 (2):309-323. https://doi.org/10.1364/ BOE.6.000309

38. Lee HT, Ota-Setlik A, Fu Y, Nasr SH, Emala CW (2004) Differential protective effects of volatile anesthetics against renal ischemiareperfusion injury in vivo. Anesthesiology 101 (6):1313-1324. https://doi.org/10.1097/ 00000542-200412000-00011

39. Hashiguchi H, Morooka H, Miyoshi $H$, Matsumoto M, Koji T, Sumikawa K (2005) Isoflurane protects renal function against ischemia and reperfusion through inhibition of protein kinases, JNK and ERK. Anesth Analg 101 (6):1584-1589. https://doi.org/10.1213/ 01.Ane.0000184044.51749.B8

40. Carraretto AR, Vianna Filho PT, Castiglia YM, Golim Mde A, Souza AV, Carvalho LR, Deffune E, Vianna PT (2013) Do propofol and isoflurane protect the kidney against ische$\mathrm{mia} /$ reperfusion injury during transient hyperglycemia? Acta Cir Bras 28(3):161-166

41. Reimann HM, Hentschel J, Marek J, Huelnhagen T, Todiras M, Kox S, Waiczies S, Hodge R, Bader M, Pohlmann A, Niendorf T (2016) Normothermic mouse functional MRI of acute focal Thermostimulation for probing 
nociception. Sci Rep 6:17230. https://doi. org/10.1038/srep17230

42. Delbridge MS, Shrestha BM, Raftery AT, El Nahas AM, Haylor JL (2007) The effect of body temperature in a rat model of renal ischemia-reperfusion injury. Transplant Proc 39(10):2983-2985. https://doi.org/10. 1016/j.transproceed.2007.04.028

43. Blaszczyk J, Kedziora J, Luciak M, Sibinska E, Trznadel K, Pawlicki L (1994) Effect of morphine and naloxone on oxidative metabolism during experimental renal ischemia and reperfusion. Exp Nephrol 2(6):364-370

44. Elkadi HK, Nghiem DD, Southard JH, Kelly KM, Olson CL (1987) Naloxone in renal ischemia: a functional and microanatomical study. J Surg Res 42(6):675-692

45. Deng J, St Clair M, Everett C, Reitman M, Star RA (2000) Buprenorphine given after surgery does not alter renal ischemia/reperfusion injury. Comp Med 50(6):628-632

46. Gonullu E, Ozkardesler S, Kume T, Duru LS, Akan M, Guneli ME, Ergur BU, Meseri R, Dora O (2014) Comparison of the effects of dexmedetomidine administered at two different times on renal ischemia/reperfusion injury in rats. Braz J Anesthesiol 64(3):152-158. https://doi.org/10.1016/j.bjane.2013.06. 002

47. Ma J, Chen Q, Li J, Zhao H, Mi E, Chen Y, Yi B, Ning J, Ma D, Lu K, Gu J (2018) Dexmedetomidine-mediated prevention of renal ischemia-reperfusion injury depends in part on cholinergic anti-inflammatory mechanisms. Anesth Analg 130(4):1054-1062. https://doi.org/10.1213/ANE. 0000000000003820

48. Zhu SH, Zhou LJ, Jiang H, Chen RJ, Lin C, Feng S, Jin J, Chen JH, Wu JY (2014) Protective effect of indomethacin in renal ischemiareperfusion injury in mice. J Zhejiang Univ Sci B 15(8):735-742. https://doi.org/10.1631/ jzus.B1300196

49. Calistro Neto JP, Torres Rda C, Goncalves GM, Silva LM, Domingues MA, Modolo NS, Barros GA (2015) Parecoxib reduces renal injury in an ischemia/reperfusion model in rats. Acta Cir Bras 30(4):270-276. https:// doi.org/10.1590/S0102865020150040000006

50. Narver HL (2017) Antimicrobial stewardship in laboratory animal facilities. J Am Assoc Lab Anim Sci 56(1):6-10

51. Gargiulo S, Greco A, Gramanzini M, Esposito S, Affuso A, Brunetti A, Vesce G (2012) Mice anesthesia, analgesia, and care, part II: anesthetic considerations in preclinical imaging studies. ILAR J 53(1):E70-E81. https://doi.org/10.1093/ilar.53.1.70

52. Zager RA (1992) Gentamicin effects on renal ischemia/reperfusion injury. Circ Res 70 (1):20-28. https://doi.org/10.1161/01.res. 70.1 .20

Open Access This chapter is licensed under the terms of the Creative Commons Attribution 4.0 International License (http://creativecommons.org/licenses/by/4.0/), which permits use, sharing, adaptation, distribution and reproduction in any medium or format, as long as you give appropriate credit to the original author(s) and the source, provide a link to the Creative Commons license and indicate if changes were made.

The images or other third party material in this chapter are included in the chapter's Creative Commons license, unless indicated otherwise in a credit line to the material. If material is not included in the chapter's Creative Commons license and your intended use is not permitted by statutory regulation or exceeds the permitted use, you will need to obtain permission directly from the copyright holder. 